\title{
A RETROSPECTIVE STUDY OF THE CONGENITAL ANOMALIES OF THE AXIAL AND APPENDICULAR SKELETON IN COW CALVES
}

\author{
MOHAMMED A.H. ABDELHAKIEM ${ }^{1}$ and MOHAMMED H. ELRASHIDY ${ }^{2}$ \\ ${ }^{1}$ Department of Surgery, Anesthesiology and Radiology, Faculty of Veterinary Medicine, \\ Assiut University, Assiut 71526, Egypt. \\ ${ }^{2}$ Department of Surgery, Anesthesiology and Radiology, Faculty of Veterinary Medicine, \\ Sohag University, Sohag 82524, Egypt.
}

Received: 15 February 2017; $\quad$ Accepted: 14 March 2017

\begin{abstract}
The present study was carried out to classify, assess and manage the different anomalies of the axial and appendicular skeleton in cow calves and to determine the outcome of possible conservative and surgical management, as well as the survival period of each case. Thirty-one calves with thirty-nine skeletal anomalies were retrospectively investigated. These animals were admitted to the clinic of Veterinary Teaching Hospital at Faculty of Veterinary Medicine, Assiut University, Egypt. The anomalies were 2 hydrocephalus, 5 meningocele, 5 cleft palate, 2 polymelia, 13 flexural deformities (FD) of the carpal and fetlock joints, 3 arthrogyroposis, 2 lordosis, 1 spinabifida, 3 anury, 1 achondroplastic malformation (bulldog calf), 1 wry nose, and 1 lateral patellar luxation. The clinical signs varied according to the different anomalies. Some of the reported anomalies had a clinical significance on the calf's awareness, suckling behavior or locomotion function such as meningocele, hydrocephalus, cleft palate, polymelia, FD, arthrogyroposis, and lateral luxation of the patella. The other defects such as lordosis, anury, non-penetrating spina bifida, and wry nose had no significant effects on the animal condition. The surgical treatment gave satisfactory results in cases of FD of the carpal and fetlock joints and in a case of polymelia which enable the treated animals to complete their life normally.
\end{abstract}

Key words: Axial, Appendicular, Anomalies, Calves

\section{INTRODUCTION}

In the recent years, the number of neonates suffering congenital anomalies increased. Congenital anomalies are defects of structure or function that appear at birth (Blowey and Weaver, 2011). The congenital anomalies affect different species of animals. The reported hereditary congenital abnormalities were around 300 defects in cattle (Huston 1993). In the literature, there are different types of anomalies that affect the different body systems (Blowey and Weaver, 2011). Congenital abnormalities of the bones may affect the axial or the appendicular skeleton. The axial skeleton abnormalities include the defects in the skull and the vertebral column. The craniofacial abnormalities include multiple defects such as wry nose, parrot mouth, pig mouth, cleft palate and incomplete closure of the frontal bone that lead to meningocele, and

Corresponding author: Dr. MOHAMMED A.H. ABDELHAKIEM E-mail address: hamdysurgery@aun.edu.eg

Present address: Department of Surgery, Anesthesiology and Radiology, Faculty of Veterinary Medicine,

Assiut University, Assiut 71526, Egypt.
Hydrocephalus (Leipold et al., 1993; Moritomo et al., 1999). The anomalies that were reported in the vertebral column are brachyspina (the spine of the animal is short due to abnormalities in its segments such as the cervical, thoracic or lumbar vertebrae) (Agerholm et al., 2006; Testoni et al., 2008), hemiveretebra, transitional vertebra, spina bifida, and some defects of the caudal vertebrae that form the tail such as agenesis of the tail (anury), wry tail, brachyury and polyury (Moritomo et al., 1995, Shaw 1992).

The congenital anomalies of the appendicular skeleton include malformations (for instances, the syndactyly, polydactyly, polymelia), angular (varus and valgus) and flexural deformities (contracted tendon and arthrogyroposis) (Adams, 2006; Andrews, 2004; Ducharme, 2004; Greet, 2000; Schneider, 1989; Weaver et al., 2005).

This study aimed to through the light on the most common congenital anomalies that affect the cattle breed in Assiut Governorate, Egypt, with special reference to the medical and the surgical treatment of some of them. Moreover, the survival period of the treated animals was investigated and recorded. 


\section{MATERIALS AND METHODS}

\section{Animals}

This study included 31 cow calves. These animals were admitted to the Department of Surgery, Anesthesiology and Radiology, Veterinary Teaching Hospital, Assiut University, Assiut, Egypt in the period between January 2009 and November 2016. They suffered from different anomalies of the skeletal system. Calves were admitted during the first five months after birth.

\begin{abstract}
Anomalies
Case history was taken from the owners about breeding system, history of anomalies in previous births and infection developed during the gestation period. The animals were examined systematically and the different anomalies of the skeletal system were recorded. Moreover, the other anomalies that affect other body parts or systems were taken in consideration. The animals were examined from cranial to caudal direction, starting from the head, neck, forelimbs, trunk and finally the hindlimbs. The anomalies were recorded either affect one side or both sides and the severity or the degree of the defects were evaluated to decide the management plans.
\end{abstract}

The conservative and surgical treatment

The possible conservative or surgical management were performed in some anomalies as following:

\section{Hydrocephalus}

Two cases of hydrocephalus were reported in this study (Fig. 1). The management was focused on the supportive treatment such as tonics (Norbrook Multivitamin Injection, $5 \mathrm{ml} /$ animal/daily/ 5 days). Nonsteroidal anti-inflammatory agents (Diclofenac sodium $2.5 \mathrm{mg} / \mathrm{kg}$ (Declophen $75 \mathrm{mg} / 3 \mathrm{ml}$ ampoule, Pharco co. Alexandria)) were prescribed for 2 to 3 days to ease discomfort and encourage nursing.

\section{Meningocele}

Five cases of meningocele were recorded in this study. Three out of the five cases of meningocele were treated surgically by total excision the external and internal layers of the sac. The area of operation was prepared aseptically in a routine manner. The cerebrospinal fluid (CSF) was aspirated under complete aseptic condition. The circular field block was used to desensitize the operative field through the circumferencial s/c injection of lidocaine $\mathrm{Hcl} 1 \%$ (Debocaine 2\% Sigma-Tec pharmaceutical Indust. Co. Packed by: AL-Debeiky pharmaceutical industries Co. A.R.E) at the neck of external sac. The base of the meningocele was clamped using long artery forceps. The external and internal layers of meningocele were excised above the clamp about $1 \mathrm{~cm}$. The internal layer was sutured with simple interrupted pattern using chromic gut no. 0 then the outer layer was sutured by simple interrupted pattern using silk no. 1 and traumatic needle. (Fig.2). An adhesive bandage was applied above the stitches. A broad spectrum antibiotic was prescribed for 5 days $(1 \mathrm{ml} / 25 \mathrm{~kg}$ of Pen-strep (Procaine Penicillin G, Dihydrostreptomycin), Norbrook, Egavet co., Giza, A.R.E) postoperatively.

One of the remained two cases of meningocele was treated medically by using mannitol $20 \%(500 \mathrm{ml}$ bottle: 1 gram $(5 \mathrm{ml}) / \mathrm{kg} /$ day for 10 days, Nile co., A.R.E). This case was followed up until 47 days from its admission to the Veterinary Teaching Hospital (VTH). The fifth case was not treated according to the owner request.

\section{Cleft palate (palatoschisis)}

Five cases of cleft palate were recorded. Surgical treatment was feasible only in one case out of the five calves. The rostral two thirds of the length of the cleft palate was sutured through a combination of unilateral mucosal inverting flap and buccal advancement flap using prolene no. 0 and interrupted suture pattern (Fig. 3). The owners of the remained four (untreated) calves were advised to introduce the milk and food to the animals when their head and neck were kept extended to facilitate the swallowing of the food and avoids the drenching pneumonia.

\section{Polymelia}

Two cases of polymelia were recorded in this study (Fig.4). The first one was a complete extra-pelvic limb originated from the dorsal midline of the thoracolumbar spine. The second was admitted with two incomplete extra-thoracic limbs that originated at the dorsal midline between the two scapular bones. The first case was surgically treated, after the aseptic preparation and circular field block were performed. A circumferential skin incision at the junction between the extra-limb and the back was done. Blunt dissection was performed and the large blood vessels were double ligated using no. 2 chromic gut and transacted between the two ligatures. Blunt dissection was completed and the entire extra-limb was removed. The skin defect on the back was closed by the simple interrupted pattern using no. 1 silk and sharp needle. A broad spectrum antibiotic (Pen-strep (Procaine Penicillin G, Dihydrostreptomycin): $1 \mathrm{ml} / 25$ Kg.B.W) was prescribed for 5 days postoperatively. The second calf was not subjected to treatment due to owner request and was not followed-up.

\section{Flexural deformities (FD) (contracted tendons)} Thirteen calves with flexural deformities were recorded in this work. Eight out of thirteen had FD of the metacarpophalangeal joints. They were 7 bilateral affections (Fig. 5A) and one unilateral affection in the 
left fetlock of the thoracic limb. The five remained cases were in the carpal joints. They were 2 bilateral affections and 3 unilateral affections ( 2 in the left and 1 in the right carpus) (Fig. 5B). The flexed joints were checked preoperatively whether the limbs could be extended manually or not. The preoperative assessment of the surgical outcomes was determined according to the manual examination of the flexed joints.

Seven out of eight cases of the flexural deformities of the metacarpopalangeal joints were treated. Six cases were treated surgically, and one case was treated medically using $10 \mathrm{mg} / \mathrm{kg}$. of oxytetracyclin, daily for 10 days (Oxyject 5\%, ADWIA Pharmaceutical co., A.R.E). However, one case could not be treated. The surgical treatment of the FD of the metacarpophalangeal joints was carried out as follows: The calf was placed in lateral recumbency with the operated limb uppermost. The metacarpal region was prepared aseptically. Linear infiltration anesthesia was performed using $1 \%$ lidocaine $\mathrm{Hcl}$ (Debocaine 2\% Sigma-Tec pharmaceutical Indust. Co. Packed by: AL-Debeiky pharmaceutical industries Co. A.R.E). A tourniquet was applied just distal to the carpal joint for hemostasis during the operation. A 6 $\mathrm{cm}$ linear incision was performed on the lateral aspect of the metacarpal region over the flexor tendons. The incision was passed through the skin, subcutaneous tissue and the fascia. Blunt dissection was done to separate the superficial digital flexor tendon (SDFT) from the deep digitalflexor tendon (DDFT) using hemostats. The lateral palmar nerve and adjacent vessels were carefully retracted dorsally during dissection. The SDFT was severed first and the angle of flexion of the fetlock joint was checked. The DDFT was severed when the extension of the limb was not achieved. The subcutaneous tissue and skin were closed by the cross-mattress pattern using braided silk no. 2 and sharp needle. The tourniquet was released. The limbs were fixed externally using a combination of the splints on the Palmar aspect of the limb and plaster of Paris bandage extending from the claw to above the level of the carpus. The external coapitation lasted for 45 days postoperatively. The operated calf received broad spectrum antibiotic for 5 days $(1 \mathrm{ml} / 25 \mathrm{~kg}$ of pen-strep, Egavet co.,) Postoperatively.
The surgical treatment of the FD of the carpal joints was performed in 4 (3 unilateral and 1 bilateral) out of 5 calves. However, one case with bilateral FD was not treated, as the case was accompanied with other anomalies had the priority of management. Treatment was performed by severing of SDFT and DDFT at the level of the carpal canal, which was surgically exposed at the caudomedial aspect of the carpal joint after the incision of the flexor retinaculum. The medial palmar nerve and artery were preserved during the operation through the lifting up of these structures using curved hemstat. Then, all the other steps of the surgical treatment of FD of the fetlock joints were carried out.

\section{Arthrogyroposis}

Arthrogyroposis was recorded in 3 calves (Fig. 6A). The clinical examination, number of affected joints, number of affected limbs, presence of joint ankylosis, abnormal joint conformation (extension vs flexion\& varus vs valgus), and radiographic examination (Fig. $6 \mathrm{~B} \& \mathrm{C})$ were used to distinguish the arthrogyroposis from the contracted tendons. Only, the medical management was suggested for animals. Oxytetracyclin $5 \%(10 \mathrm{mg} / \mathrm{Kg}$. B.W) for 7 days was injected intramuscular.

\section{Other anomalies}

Two cases of lordosis were noticed in this work. These cases were examined clinically and confirmed radiographically (Fig. 7A). There was no any treatment prescribed for these animals except if they had any other abnormalities.

Spina bifida is reported in one calf (Fig. 7B). The case was non penetrating form, so it was managed by using zink oxide ointement on the intact skin around the area of eptheliogenesis imperfecta. Moreover, the external bandage (gauze, thin layer of cotton and adhesive tape) was applied. $\mathrm{AD}_{3} \mathrm{E}$ vitamins (5ml/ animal/ day) were injected intra-muscular for 7 days to enhance eptheliogenesis.

Achondroplastic malformation (Bulldog calf) in one case (Fig. 1B), wry nose (Fig. 8) in one case, anury (Fig. 9) in three cases, and lateral patellar luxation (Fig. 10 A\&B) in one case were recorded in the study, but were not subjected to any type of treatment. 

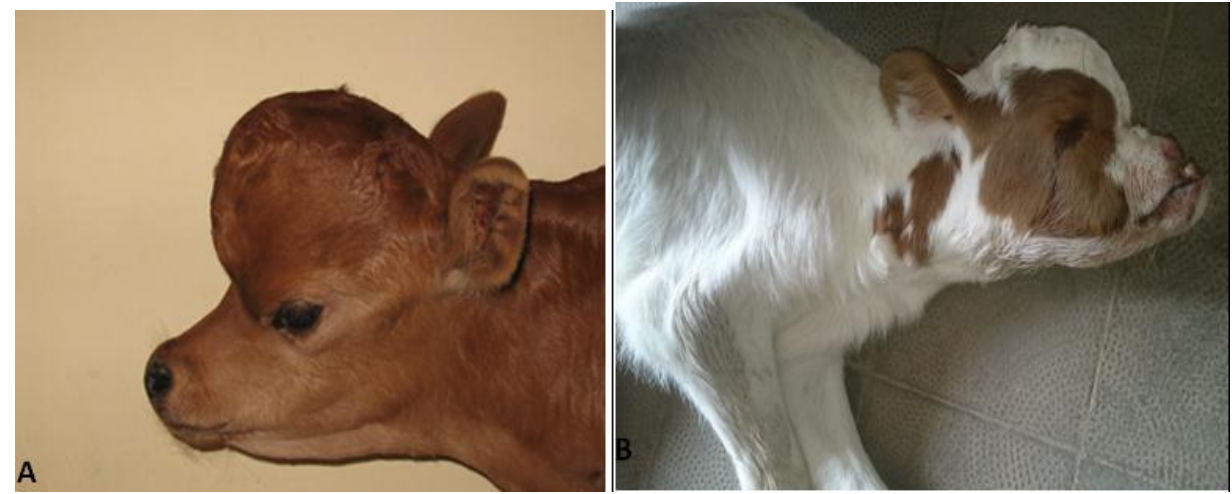

Fig.1. 3- days, old calf with a dome shaped forehead as a characteristic sign of hydrocephalus (A), and 2- days old calf that had different deformities in the head such as hydrocephalus, achondroplastic malformation (bulldog calf), anophthalmia and prognathism (B).
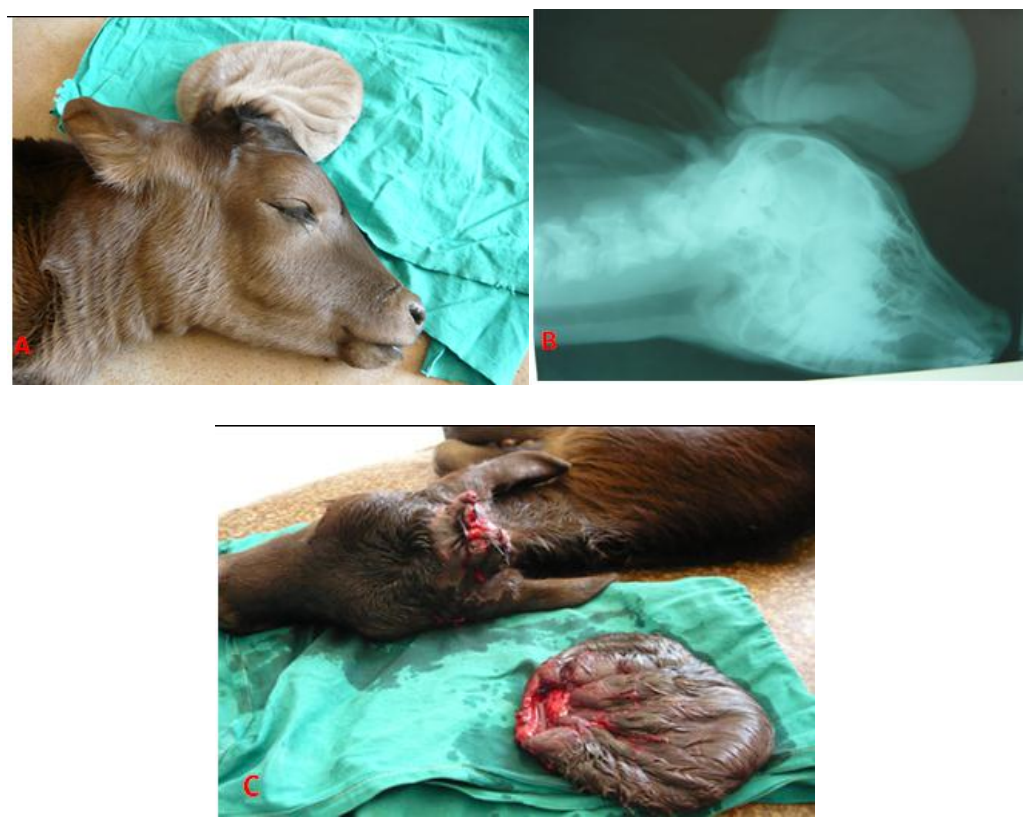

Fig.2. 2- days old, calf suffered meningocele (A), lateral radiograph of the same calf with meningocele (B), The surgical removal of the external and internal sacs of the meningocele at the base of the cranial bones (C).

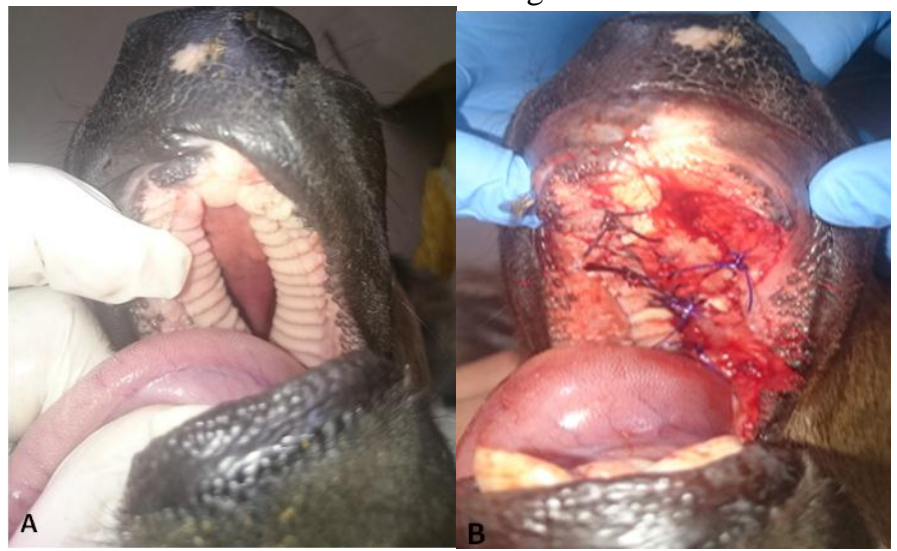

Fig.3. Cleft palate in 4 days-old male calf (A), and the surgical treatment using combination of unilateral mucosal inverting flap and buccal advancement flap (B). 

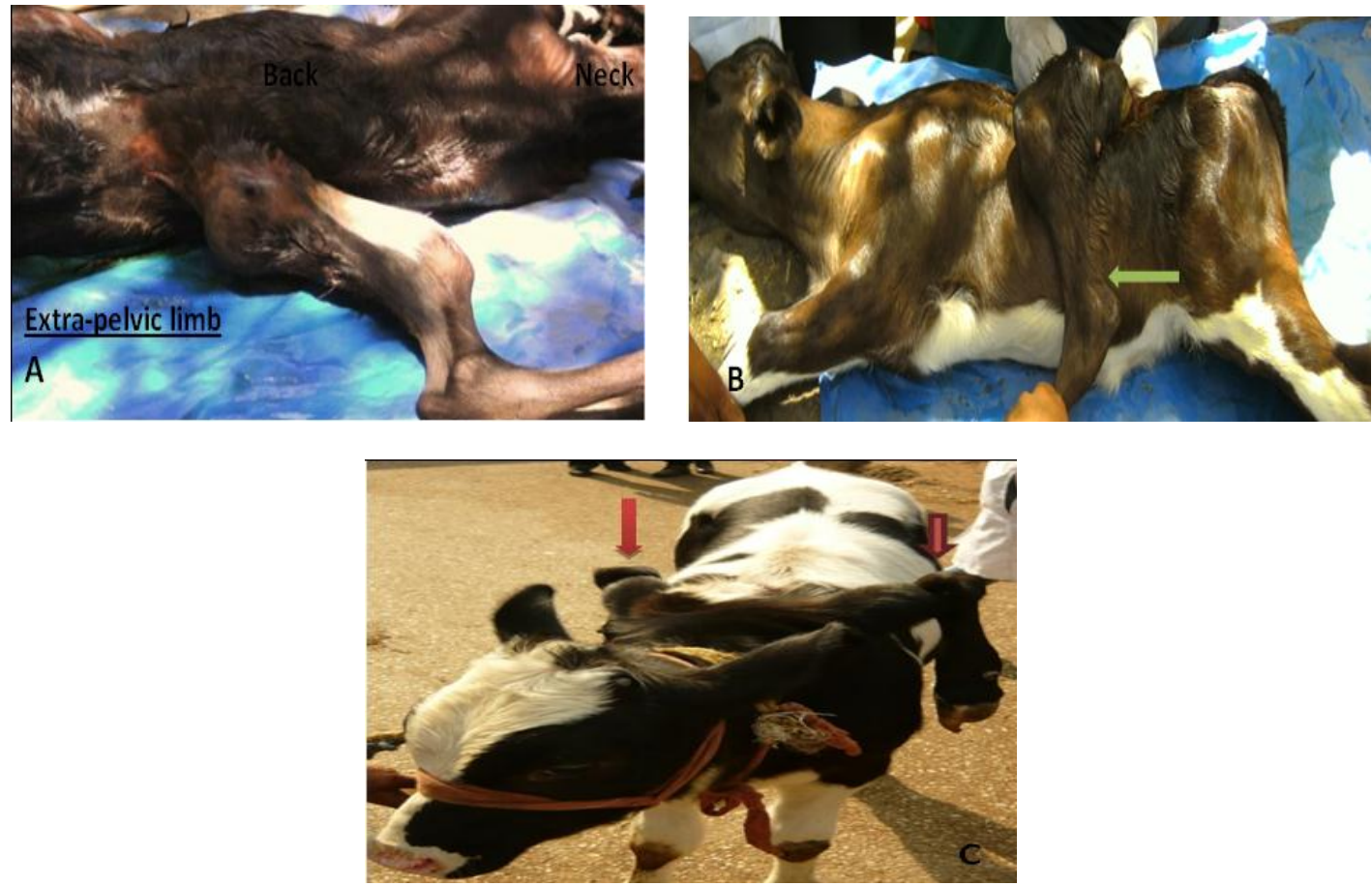

Fig. 4: Polymelia (an extra -pelvic limb) of 5-days old calf at the thoracolumbar region (A\&B (arrow)), and two extra-thoracic limbs (arrows) arose from the cranial thaoracic spine (C).
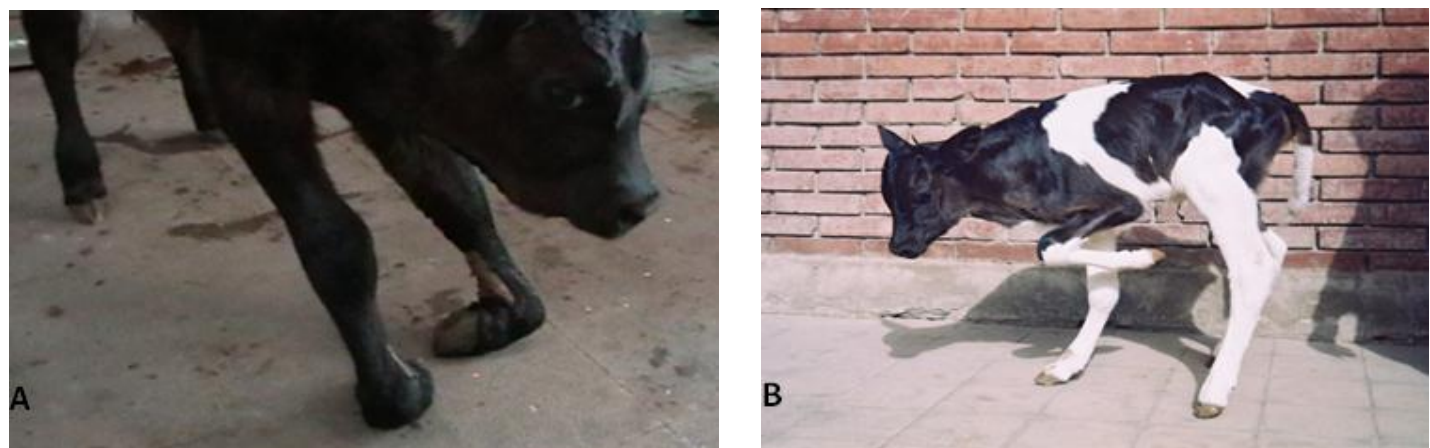

Fig. 5: Contracted tendons lead to the flexion of the fetlock joints of the two forelimbs (A), and the flexion of the carpus of the left forelimb (B) in newly born calves.
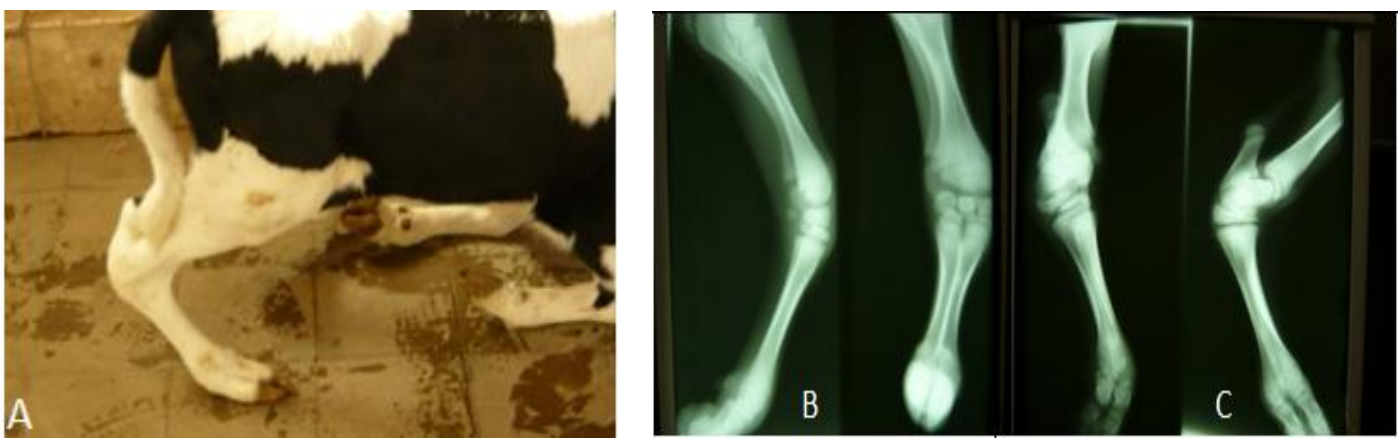

Fig. 6: Arthrogyroposis in 5-daysold male calf. A: Deformities (ankylosed flexion) of the carpal and tarsal joints. B: Lateral and oblique dorso-palmar radiographic views of the right forelimb with abnormal conformation of the distal end of the radius, proximal and distal rows of the carpal bone. Shortage of the metacarpal bone and partial fusion of the two digits (incomplete syndactyle) also were observed. C: Lateral and oblique dorso-plantar view of the right hindlimb with abnormal conformation of the tarsus especially between the distal end of the tibia and talus. 

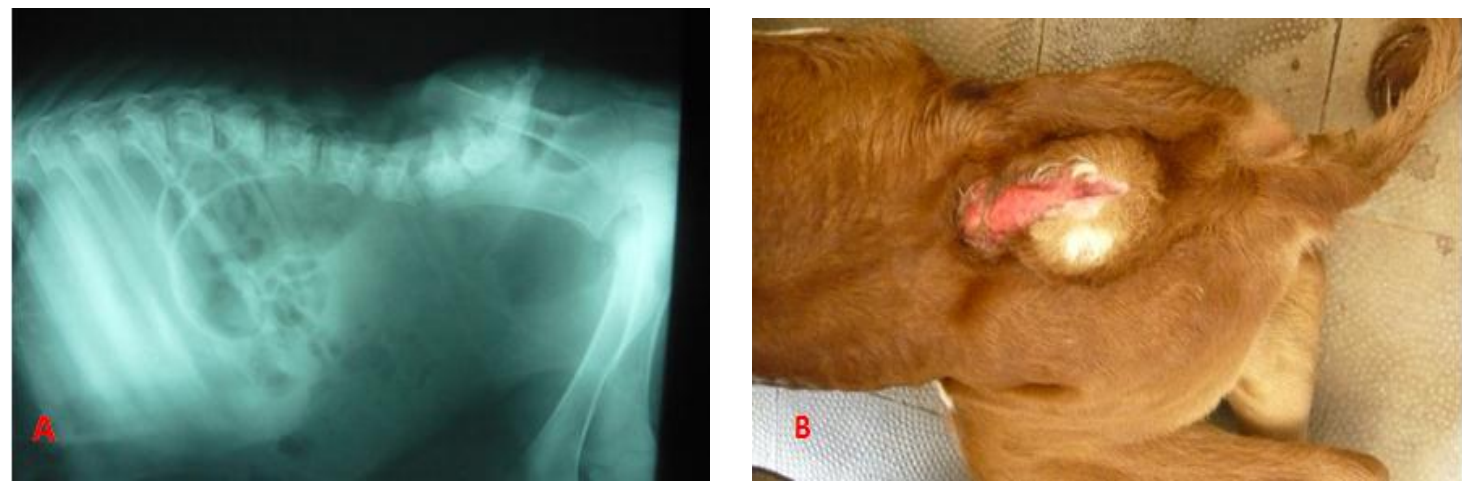

Fig. 7: Lateral radiographic view of the abdomen of 2-days old calf suffered atresia ani et recti with lordosis (ventral deviation) of the lumbar vertebrae (A), and non-peneterating spina bifida of 3 days old calf (B).

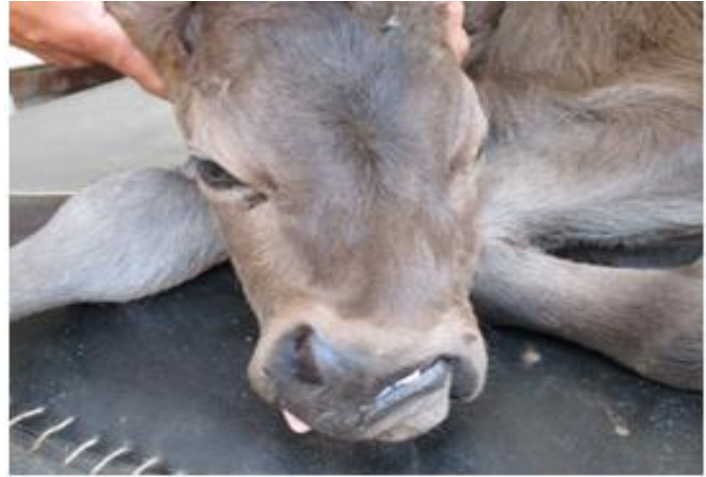

Fig. 8: 3-days old calf had wry nose, harelip.

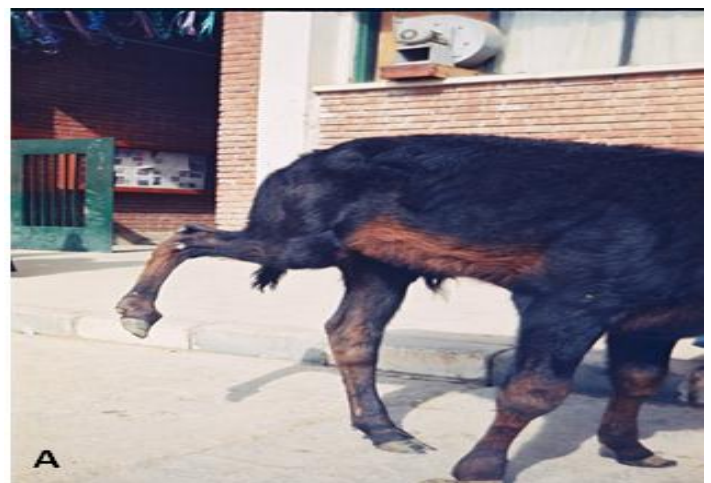

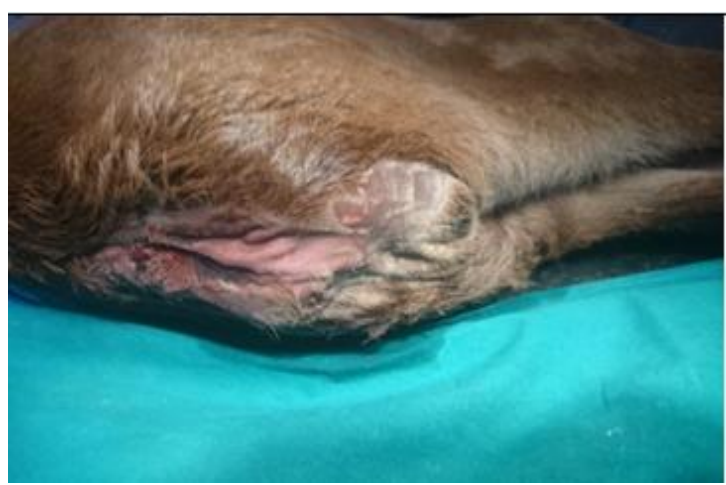

Fig. 9: 2-days old male calf had an agenesis of the tail (anury), in addition to atresia ania and short rectum.

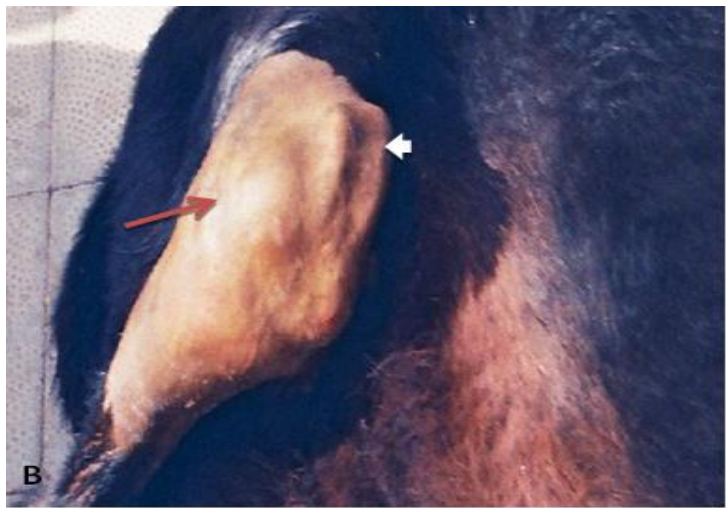

Fig. 10: (A) Lateral luxation of the patella in a male calf showing severe degree of flexion of the stifle and hock joints. (B): Close-up of figure A showing lateral luxation of the patella (arrow) relative to the femoral trochlea (arrow-head).

\section{RESULTS}

The total number of animals in this study was thirtyone cow calves. Age of the calves varied from 1 day to 5 months. Calves were twenty-two males, three females and the gender of remained calves were not recorded.

The total number of axial and appendicular anomalies that reported in this study was thirty-nine anomalies. These anomalies represented twelve forms of anomalies that were summarized in (table $1 \& 2$ ). The signs varied according to the type of the anomaly, the severity of the case, the presence of different anomalies in the same animal and the number of the affected limbs (table1\&3). Some of the anomalies such as the wry nose, lordosis, non-penetrating spina bifida, and anury did not have clinical significance in the calves. The other anomalies such as meningocele, hydrocephalus, cleft palate, contracted tendons, polymelia and arthrogyroposis had clinical effects such as the calf's awareness, suckling behavior or locomotion function (table 1). 


\section{Hydrocephalus}

Two cases of hydrocephalus were noticed in this study (table 3 ). The first case had a prominent domeshaped forehead (Fig. 1A). The case could not be followed up after supportive treatment. The second calf suffered different congenital defects. Congenital achondroplasia (bulldog calf), right side anophthalmia, cleft palate, progranthism, and anury were associated the hydrocephalus in the second calf (table, 2\&3, Fig. 1B). This animal could not stand, and nurse. It died on the $5^{\text {th }}$ day of its birth.

\section{Meningocele}

The 5 cases of meningocele varied in the size of the swelling, the frontal bone defects and the treatment protocol. The three cases that were treated surgically, died within the few days post-operation. One case did not get the treatment, and was not followed up to know its fate. One calf was treated medically through intravenous administration of mannitol $20 \%$. This calf survived till fifty days from its birth and then slaughtered after its recumbency for a few days (table $3)$.

\section{Cleft palate (palatoschisis)}

Five cases had a cleft palate (oronasal fistula) were noted in this study. All Animals with cleft palate presented with nasal regurgitation of milk (4 calves), water, and food material (1 calf) immediately after eating. The cleft palate involved the hard and soft palate in all animals. One case out of five was surgically treated using the combination of unilateral mucosal inverting flap and buccal advancement flap. The surgical treatment closed about the rostral two thirds of the defect, but the caudal portion was not sutured (slit like). This animal suffered other anomalies that accompany the cleft palate such as atresia ani, and the FD of the carpal joints. Moreover, the condition of the animal at its time of admission to the hospital was not in a good physical state. The calf was followed up but it died 2 days after surgery (table $3)$.

\section{Polymelia}

The two calves of polymelia were male animals. Their age was 1 month and 3 months. The surgically treated calf was improved without any complication. Moreover, the body gain of this animal increased (table 3).

\section{Flexural deformities (FD) (contracted tendons)}

The flexural deformities or the contracted tendons of the fetlock and carpal joints were recorded in thirteen calves ( 8 cases in the fore fetlock and 5 cases in the carpus). The bilateral affection of the fetlock joints was recorded in seven cases, while unilateral affection of fetlock joint was noticed in one left forelimb. Two calves had a bilateral affection of the carpal joints, and three calves had unilateral contracted tendons of the carpal joint (two left carpal joints and one right carpal joint) (table 3). Eleven calves out of thirteen were male, one female and the remained one was not recorded.
Seven out of eight cases of the flexural deformities of the metacarpopalangeal joints were treated. Six cases were treated surgically, and one case was treated medically using oxytetracyclin 5\%. The calf that treated by intramuscular injection of oxytetracycline was completely cured within ten days from the beginning of treatment. Five out of six cases of FD of the fetlock joints that were surgically treated cured completely and the animals walked and ran normally. However, the remaining one calf that suffered a wry nose and harelip, walked normally and reached his dam for nursing but it had stunt of growth (table 3 ).

Four ( 3 unilateral and 1 bilateral) out of 5 calves with FD in the carpal joint were treated surgically. However, remaining one case with bilateral FD that suffered cleft palate and atresia ani, the priority of treatment was to that accompanied anomalies. Surgical treatment gave satisfactory results and the calf walked and ran on the operated limb in two unilateral cases (one right and one left) and gave slight improvement in one left unilateral case. However, the remainder calf operated for bilateral FD could not be followed up (table 3).

\section{Arthrogyroposis}

Three cases of variant degrees of arthrogyroposis were recorded in this study. These cases were recorded in male Frisian calves. The signs associated with the affected calves differed according the number of affected limbs, number of affected joints in each limb and the degree of the flexion or extension of the joints. One calf had bilateral rigid flexion and deformity of the hock joints. This calf could reach its dam, but unfortunately it had a cleft palate that hinders the animal feeding. The muscular atrophy of the caudal thigh associated the arthrogyroposis. Although the animal was treated medically by oxytetracycline $5 \%$, it died on the $8^{\text {th }}$ day of birth. The second calf had affection in the four limbs. It suffered bilateral rigid flexion of the carpal and tarsal joints. Moreover, the distal limbs below the tarsus were deviated outward (bilateral valgus). The lateral digit of the claws of the fore and hind-limbs was shorter than the medial one. The case associated with atrophy of the muscles of the thigh. The animal could not walk, but move like a rabbit in hopping form. The last case of arthrogyroposis had bilateral rigid flexion of the carpal and tarsal joints which make the calf unable to walk and reach its mother for nursing. The case number 2 and 3 were treated medically but without improvement (table 3).

\section{Other anomalies}

Axial and appendicular anomalies such as lordosis, Achondroplastic malformation (Bulldog calf), wry nose, anury and lateral patellar luxation did not receive any treatment. 
Table 1: Types, number and prominent signs of the axial and appendicular skeleton anomalies.

\begin{tabular}{|c|c|c|c|}
\hline Number & Affection & $\begin{array}{l}\text { Replicate of } \\
\text { affections }\end{array}$ & Prominent clinical signs \\
\hline 1 & Hydrocephalus & 2 & Enlargement of the head, and dome-shaped forehead \\
\hline 2 & Meningocele & 5 & Dullness, ataxia \\
\hline 3 & Cleft palate & 5 & prescence of the milk or food at the nostrils \\
\hline 4 & Polymelia & 2 & Presence of one extra-limb or more anywhere on the body surface \\
\hline 5 & $\begin{array}{l}\text { flexural deformities } \\
\text { (Contracted tendon) }\end{array}$ & 13 & $\begin{array}{l}\text { Signs varied according to the degree of joint flexion, the number of } \\
\text { affected joints and number of affected limbs. It started from lameness } \\
\text { to animal difficulty to stand on the forelimb and to reach to its dam for } \\
\text { feeding. }\end{array}$ \\
\hline 6 & Arthrogyroposis & 3 & $\begin{array}{l}\text { Ankylosed flexion of more than one joint in different limbs, animal } \\
\text { hardly to stand up and walk }\end{array}$ \\
\hline 7 & Lordosis & 2 & Ventral deviation of the lumbar vertebrae without clinical signs \\
\hline 8 & Spina bifida & 1 & $\begin{array}{l}\text { Wound at the dorsal midline of the vertebral column without clinical } \\
\text { signs }\end{array}$ \\
\hline 9 & Bulldog calf & 1 & Short head and prognathism \\
\hline 10 & Wry nose & 1 & Snoring sound associated with increase of respiratory rate \\
\hline 11 & $\begin{array}{l}\text { Anury (agenesis of } \\
\text { the tail) }\end{array}$ & 3 & Absence of the tail (caudal vertebrae) \\
\hline 12 & $\begin{array}{l}\text { Congenital luxation } \\
\text { of the patella }\end{array}$ & 1 & Severe flexion of the stifle and hock joints \\
\hline Total & & 39 & \\
\hline
\end{tabular}

Table 2: Distribution of the anomalies among the cases.

\begin{tabular}{|c|c|c|c|c|c|c|c|c|c|c|c|c|c|c|c|}
\hline & $\begin{array}{l}\text { हैँ } \\
\text { के }\end{array}$ & 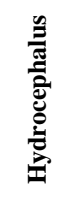 & 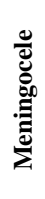 & 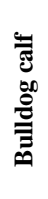 & $\begin{array}{l}\ddot{8} \\
\stackrel{8}{3} \\
3\end{array}$ & 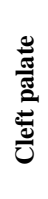 & & 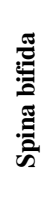 & $\begin{array}{l}\frac{n}{0} \\
\frac{0}{0} \\
0 \\
0 \\
0\end{array}$ & $\vec{E}$ & 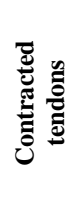 & 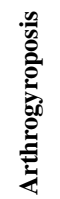 & 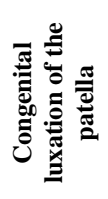 & 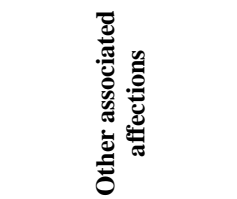 & 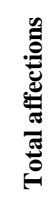 \\
\hline$\frac{1}{1}$ & calf & & & & & & & & & & & & & & \\
\hline 2 & calf & & & & & & & & & & & & & $\begin{array}{l}\text { Overshot mandible, } \\
\text { right anophthalmia }\end{array}$ & \\
\hline 3 & calf & & & & & & & & & & & & & & \\
\hline 4 & calf & & & & & & & & & & & & & & \\
\hline 5 & calf & & & & & & & & & & & & & & \\
\hline 6 & calf & & & & & & & & & & & & & & \\
\hline 7 & calf & & & & & & & & & & & & & & \\
\hline 8 & calf & & & & & & & & & & & & & Hare lip & \\
\hline 9 & calf & & & & & & & & & & & & & & \\
\hline 10 & calf & & & & & & & & & & & & & Atresia ani & \\
\hline 11 & calf & & & & & & & & & & & & & & \\
\hline 12 & calf & & & & & & & & & & & & & & \\
\hline 13 & calf & & & & & & & & & & & & & & \\
\hline 14 & calf & & & & & & & & & & & & & & \\
\hline 15 & calf & & & & & & & & & & & & & Atrsia ani\& RVF & \\
\hline 16 & calf & & & & & & & & & & & & & Atresia ani\& recti & \\
\hline 17 & calf & & & & & & & & & & & & & $\begin{array}{l}\text { Atresia ani and short } \\
\text { rectum }\end{array}$ & \\
\hline 18 & calf & & & & & & & & & & & & & & \\
\hline 19 & calf & & & & & & & & & & & & & & \\
\hline 20 & calf & & & & & & & & & & & & & & \\
\hline 21 & calf & & & & & & & & & & & & & & \\
\hline 22 & calf & & & & & & & & & & & & & & \\
\hline 23 & calf & & & & & & & & & & & & & & \\
\hline 24 & calf & & & & & & & & & & & & & & \\
\hline 25 & calf & & & & & & & & & & & & & & \\
\hline 26 & calf & & & & & & & & & & & & & & \\
\hline 27 & calf & & & & & & & & & & & & & & \\
\hline 28 & calf & & & & & & & & & & & & & & \\
\hline 29 & calf & & & & & & & & & & & & & & \\
\hline 30 & calf & & & & & & & & & & & & & & \\
\hline 31 & calf & & & & & & & & & & & & & & \\
\hline total & 31 & 2 & 5 & 1 & 1 & 5 & 2 & 1 & 2 & 3 & 13 & 3 & 1 & & 39 \\
\hline
\end{tabular}


Table 3: Illustrate form, management and fate of each case.

\begin{tabular}{|c|c|c|c|c|c|}
\hline Case no. & Animal & Sex & Affections & Treatment & Follow up and fate \\
\hline 1 & calf & & Hydrocephalus & Supportive treatment & not followed up \\
\hline 2 & calf & $\mathrm{F}$ & $\begin{array}{c}\text { Hydrocephalus, bulldog head, cleft } \\
\text { palate, anury }\end{array}$ & Supportive treatment & Died at the 5 th day of birth \\
\hline 3 & calf & M & Meningocele & Surgically treated & $\begin{array}{c}\text { Died within week } \\
\text { posoperation }\end{array}$ \\
\hline 4 & calf & $\mathrm{M}$ & Meningocele & Sugical treatment & Died at 2nd day postoperation \\
\hline 5 & calf & & Meningocele & Sugical treatment & $\begin{array}{c}\text { Died within } 24 \text { hours } \\
\text { potoperation }\end{array}$ \\
\hline 6 & calf & & Meningocele & No treatment & It was not followed up \\
\hline 7 & calf & $\mathrm{M}$ & Meningocele & Mannitol & 50 days, then slaughter \\
\hline 8 & calf & M & $\begin{array}{l}\text { Wry nose, hare lip and flexural } \\
\text { deformities at the two fetlock } \\
\text { joints of the forelimbs }\end{array}$ & $\begin{array}{l}\text { Surgical treatment of the } \\
\text { FD of the fetlock joints }\end{array}$ & $\begin{array}{l}\text { Animal walk and run on its } \\
\text { limb but it is stunded in } \\
\text { growth }\end{array}$ \\
\hline 9 & calf & $\mathrm{M}$ & Cleft palate, arthrogyroposis & Medical treatment & Died at 8th day of birth \\
\hline 10 & calf & M & $\begin{array}{l}\text { Cleft palate, Flexural deformities } \\
\text { of the two carpal joints, Atresia ani } \\
\text { with short rectum }\end{array}$ & $\begin{array}{l}\text { Surgical treatment of the } \\
\text { cleft palate, and the } \\
\text { atresia ani }\end{array}$ & Died at 2nd day of operation \\
\hline 11 & calf & & Cleft palate & No treatment & not followed up \\
\hline 12 & calf & & Cleft palate & No treatment & not followed up \\
\hline 13 & calf & M & $\begin{array}{l}\text { Polymelia (single hindlimb } \\
\text { attached to the back) }\end{array}$ & Surgical removal & Good condition calf \\
\hline 14 & calf & M & $\begin{array}{l}\text { Polymelia ( } 2 \text { incomplete forlimbs } \\
\text { originated from the dorsal midline } \\
\text { of the caudal cervical spine) }\end{array}$ & No treatment & It was not followed up \\
\hline 15 & calf & $\mathrm{F}$ & $\begin{array}{l}\text { Lordosis, spina bifida, atresia ani } \\
\text { and rectovaginal fistula }\end{array}$ & $\begin{array}{l}\text { Surgical treatment of } \\
\text { atresia ani and } \\
\text { rectovaginal fistula } \\
\end{array}$ & Animal had a good condition \\
\hline 16 & calf & M & $\begin{array}{l}\text { lordosis, anury and atresia ani and } \\
\text { recti }\end{array}$ & $\begin{array}{l}\text { Surgical treatment of } \\
\text { atresia ani and recti }\end{array}$ & It was not followed up \\
\hline 17 & calf & M & Anury, atresia ani and short rectum & Typhlostomy & $\begin{array}{c}\text { The animal was not followed } \\
\text { up }\end{array}$ \\
\hline 18 & calf & M & $\begin{array}{l}\text { FD of both fetlock joints of the } \\
\text { forelimbs }\end{array}$ & $\begin{array}{l}\text { Oxytetracyclin }(10 \mathrm{mg} / \mathrm{kg} \\
\text { bw daily for } 10 \text { days })\end{array}$ & $\begin{array}{c}\text { Good results (animal can walk } \\
\text { normally on its forelimb) }\end{array}$ \\
\hline 19 & calf & M & $\begin{array}{c}\text { FD of both fetlock joints of the } \\
\text { forelimbs }\end{array}$ & Surgical treatment & $\begin{array}{c}\text { Good results (animal can walk } \\
\text { normally on its forelimb) }\end{array}$ \\
\hline 20 & calf & M & $\begin{array}{l}\text { FD of both fetlock joints of the } \\
\text { forelimbs }\end{array}$ & Surgical treatment & $\begin{array}{c}\text { Good results (animal can walk } \\
\text { normally on its forelimb) }\end{array}$ \\
\hline 21 & calf & M & $\begin{array}{l}\text { FD of both fetlock joints of the } \\
\text { forelimbs }\end{array}$ & Surgical treatment & $\begin{array}{c}\text { Good results (animal can walk } \\
\text { normally on its forelimb) }\end{array}$ \\
\hline 22 & calf & M & $\begin{array}{l}\text { FD of both fetlock joints of the } \\
\text { forelimbs }\end{array}$ & Surgical treatment & $\begin{array}{c}\text { Good results (animal can walk } \\
\text { normally on its forelimb) }\end{array}$ \\
\hline 23 & calf & M & $\begin{array}{l}\text { FD of both fetlock joints of the } \\
\text { forelimbs }\end{array}$ & No treatment & It was not followed up \\
\hline 24 & calf & M & FD of left fetlock of forelimb & Surgical treatment & $\begin{array}{c}\text { Good results (animal can walk } \\
\text { normally on its forelimb) }\end{array}$ \\
\hline 25 & calf & M & FD of both carpal joints & Surgical treatment & $\begin{array}{l}\text { The owner could not be } \\
\text { followed up }\end{array}$ \\
\hline 26 & calf & M & $\begin{array}{l}\text { FD of the carpal joint of the right } \\
\text { forelimb }\end{array}$ & Surgical treatment & $\begin{array}{c}\text { Good results (animal can walk } \\
\text { normally on its forelimb) }\end{array}$ \\
\hline 27 & calf & & $\begin{array}{l}\text { FD of the carpal joint of the left } \\
\text { forelimb }\end{array}$ & Surgical treatment & $\begin{array}{l}\text { Slight improvement, but the } \\
\text { animal could not walk } \\
\text { normally }\end{array}$ \\
\hline 28 & calf & $\mathrm{F}$ & FD at the left carpal joint & Surgical treatment & $\begin{array}{c}\text { Good results (animal can walk } \\
\text { normally on its forelimb) }\end{array}$ \\
\hline 29 & calf & M & $\begin{array}{c}\text { Arthrogyroposis of four limbs } \\
\text { (carpal, tarsal and hind fetlock } \\
\text { joints) }\end{array}$ & Medical treatment & No improvement \\
\hline 30 & calf & M & $\begin{array}{l}\text { Arthrogyroposis at the fetlock and } \\
\text { carpal joints of the both forelimbs }\end{array}$ & Medical treatment & No improvement \\
\hline 31 & calf & M & $\begin{array}{l}\text { Lateral luxation of the patella of } \\
\text { the right hindlimb }\end{array}$ & No treatment & It was not followed up \\
\hline
\end{tabular}




\section{DISCUSSION}

In this study, the authors strived to outline the most common anomalies that affect the axial and appendicular skeleton, with special reference to the management of some of them. Moreover, the effect of the medical or surgical treatment on the survival period of the animals was evaluated and determined, which could be helpful to understand the clinical significance of each anomaly and the expected outcome of treatment.

Firstly, the results of this study revealed that the total recorded anomalies were thirty-nine axial and appendicular skeletal anomalies in thirty-one calves. The flexural deformities of the fetlock and carpal joints represented the highest percentage of skeletal anomalies $(13 / 39 ; 33.33 \%)$, followed by the meningocele $(5 / 39 ; 12.8 \%)$, and cleft palate $(5 / 39$; $12.8 \%$ ). The results of this study showed that the male animals are highly affected with skeletal anomalies, which may suggest that these anomalies might be sex linked disorders.

The results of this study revealed that the skeletal anomalies may occur independently or associated with other anomalies which affect other body parts. Similar results were reported by Shupe et al. (1968); Konno et al. (1982) and Ducharme, (2004). So, Hahn, (2008). They recommended thorough examination of the newly born animals suffering any defects.

It was reported that the congenital anomalies may occur due to genetic or environmental factors or combination of both (Blowey and Weaver, 2011). In this study, the history for each case was taken from the owners, and they referred to inbreeding system, moreover, the dams of calves were pleuroparous, and these anomalies were reported for the first time according to the owners. All of these aforementioned causes may overweight the environmental than the genetic factors to cause these anomalies. In addition to, the pregnant animals may be vulnerable or liable for any type of infection which may cause defects in the embryo, or the fetus. This matter was confirmed by Konno et al. (1982), who reported that the viral infection of the fetus may lead to several anomalies such as arthrogyroposis (curled calf disease), kyphosis, lordosis, scoliosis, nonpurulent encephalitis and hydroencephalopathy.

The actual cause behind the different anomalies in animals is still unknown and further intensive studies are needed to explain the main etiology. But, according to the collected data. The owners said that the rectal examination of their animals within the first 2 months after mating for early pregnancy diagnosis. So, this environmental stress may support what was reported in the previous studies that the genetic factors may have an effect at the early stage of gestation (first 2 weeks), while the environmental effect may appear later (14-42 days of gestation) (Johnson et al., 1985 and Aiello 1998). Moreover, we could not neglect other environmental factors such as polluted food \&water and radiation.

Hydrocephalus, or water in the brain, occurred due to a brain defect and accumulation of excess fluid in the brain cavities. Most of the neonatal calves suffered hydrocephalus die either at birth or shortly afterward due to the increase of the intracranial pressure and the calves are unable to stand or nurse (Leipold et al., 1993). In this study, the hydrocephalus was recorded in two cases, which died within the first few days after birth. In this present work, the hydrocephalus was diagnosed by the presence of the dome shaped forehead. This sign is considered the most prominent sign in the hydrocephalic animal. But for more confirmation Hahn, (2008) recommended the use of advanced diagnostic imaging such as the computed tomography (CT) and magnetic resonance imaging (MRI). The CT and MRI may determine the type of hydrocephalus either internal in the ventricular system of the brain or external in the subarachnoid space (Leipold et al., 1974 and Hahn, 2008). Also, they could classify the hydrocephalus as normotensive or hypertensive according to the involvement of the brain parenchyma.

The case of meningocele that was treated medically had a somewhat longer life span relatively than the surgically treated calves. This may be attributed to the mode of action of mannitol, which decreases the intracranial pressure (ICP). The regular use of the drug keeps or decreases the ICP that was created by cerebrospinal fluid (CSF) on the brain tissue. While the surgical treatment depends on excision of the excess skin, which was considered a reservoir bag for the excess CSF. So, the operation may help the accumulated CSF in the narrow space that was created postoperatively to accelerate or hasten the early damage of the brain tissue and then the rapid deterioration of the animal. The use of mannitol $20 \%$ for management of the meningocele was quoted from the previous study that used mannitol as a medical treatment of the hydrocephalus in dogs (Harrington et al., 1996).

The cleft palate may be congenital or acquired (Gaughan et al., 2004). In this study, the cleft palate or the oronasal fistula was recorded in five cases. All the cases were congenitally affected. Two calves had the cleft palate as a sole lesion, while the other three cases suffered accompanying abnormalities which included atresia ani, FD of the carpal joints, the arthrogyroposis, hydrocephalus, achondroplastic malformation and anury. These findings were in agreement with what was reported by Andrew (2004) and Gaughan (2004). Only one case could be treated surgically. However, the other four cases could not be managed surgically due to the large gap that was present between the two shelves of the hard and soft 
palate, which did not facilitate the surgical management. The incidence of the aspiration pneumonia as a sequela of the cleft palate could not be determined. Three cases died in the first eight days after birth.

The flexural deformities of the carpal and fetlock joints may occur alone, or they may accompany other deformities which has heritable character such as cleft palate, Arthrogyroposis and dwarfism (Ducharme, 2004 and Weaver, 2004). In this study, the FD cases were associated with cleft palate, wry nose, hare lip or atresia ani.

The results of this study revealed that the incidence of FD of the fetlock and carpal joints was higher than other abnormalities as was reported by Weaver, (2004). All cases of FD that were noted in this work were categorized as a severe form where the animals could not walk to reach their mothers for nursing. Only one calf had a bilateral FD of the fetlock joints was treated medically by oxytetracycline $5 \%$. The condition of this animal improved. Ducharme, (2004) attributed these results to the relaxation effect of tetracycline on the contracted tendons of the deep and superficial digital flexor muscles.

The arthrogyroposis was recorded in three calves in this work. The anomaly affects different joints, especially the carpal and tarsal joints. The joints were ankylosed and fixed in a flexed position and difficult to be extended. Moreover, it was associated with atrophy of the muscles, especially the thigh muscle. In addition to, the lateral valgus was reported in the both hind-limbs in one calf. All of these findings were consistent with the findings that were reported in the previous literature (Konno et al., 1982; Andrews, 2004; IVIS, 2006). Arthrogyroposis may occur as a result of the affection or infection of the fetus in the $2^{\text {nd }}$ trimester (IVIS, 2006). The arthrogryroposis, cleft palate and deviated spine may be categorized under the irregular inheritance, at which the disease does not give a certain ratio but it occurs sporadically. Artificial insemination may leave such these congenital defects (Young, 2004).

The differentiation between the FD and arthrogyroposis is so important especially for taking the decision for surgical treatment. The FD causes mainly variant degrees of flexion of the carpal and fetlock joints either unilateral or bilateral. This affection could be treated surgically. The preoperative examination and attempts for stretching of the limb were crucial for treatment and expectation of the prognosis. However, arthrogyroposis affected multiple joints in the fore and hind limbs, especially the carpal and tarsal joints. There were several signs that associated the affected joints in case of arthrogyroposis. These signs were extension (rare) or flexion (common) of the affected joints, which were ankylosed or stiffed that could not be corrected.
Moreover, Angular deformities (varus or valgus) of the distal limbs below the affected joints were noticed. Atrophy of the muscles also was recorded. All of these aforementioned signs were in accordance with what were reported by Konno et al. (1982); Andrews (2004) and Ducharme (2004).

Spina bifida is one of the gross malformations of the spinal canal, which results from failure of the fusion of the two halves of the dorsal arches of the vertebrae. The vertebral defects may be associated with protrusion of the spinal cord (myelocele), meninges (meningocele), or both (meningomyelocele). The vertebral malformations and the defects of the vertebral column may or may not be associated with neurological signs (Hahn, 2008). In the present study, just one case of spina bifida was recorded and it was not accompanied with neurological manifestions, this is due to the spina bifida included the bony defects without involvement of the spinal cord and its meninges.

The patellar luxation was recorded in one calf. Its age was about 2 months. The luxation was laterally. It looks like the femoral nerve paralysis, which characterized with flexion of the stifle and hock joints and atrophy of the quadricieps muscle (Weaver, 2004). Other anomalies such as polymelia, lordosis, anury and bulldog anomaly are considered rare condition (Andrew, 2004).

In conclusion, the present study recorded that the congenital anomalies of the axial and appendicular skeleton are numerous. Some of the reported anomalies had a clinical significance on the calf's awareness, feeding or locomotion function such as meningocele, hydrocephalus, cleft palate, polymelia, FD, arthrogyroposis and lateral luxation of the patella. The other reported defects had no significant effects on the animal condition. The surgical treatment gave satisfactory results in cases of FD of the carpal and fetlock joints and in a case of polymelia.

\section{REFERENCES}

Adams, S.B. (2006): Update on flexural limb deformities. The North American Veterinary Conference. Vol. 20. ORLANDO, FLORIDA; January 7-11.

Agerholm, J.S.; McEvoy, F. and Arnbjerg, J. (2006): Brachyspina syndrome ina Holstein calf. Journal of Veterinary Diagnostic Investigation $18,418-422$.

Aiello, S.E. (1998): Congenital and inherited anomalies; The Merkveterinary manual, 8th ed, New Jersy, USA, Merkand Co., Inc., Whitehouse station, pp. 449- 455.

Andrews, A.H. (2004): Congenital Conditions. In. Bovine Medicine Diseases and Husbandry of Cattle (A.H. Andrews, A.H.; Blowey, R.W.; 
Boyd, H. and Eddy, H. Eds). $2^{\text {nd }}$ Ed. Blackwell Science Ltd. pp. 171-184.

Blowey, R.W. and Weaver, A.D. (2011): Congenital disorders. In. Color atlas of diseases and disorders of cattle. Elsevier Ltd., PP. 1-11.

Ducharme, N.G. (2004): Surgery of the calf musculoskeletal system. In. Farm animal surgery (Fubini, S. and Ducharme, N. Eds). $1^{\text {st }}$ Ed. SAUNDERS. St. Louis, Missouri. PP. 485-503.

Gaughan, EM.; Provo-Klimek, J. and Ducharme, NG. (2004): Surgery of the bovinerespiratory and cardiovascular systems. In. Farm animal surgery (Fubini, S. and Ducharme, N. Eds).

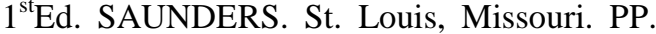
140-159.

Greet, T.R.C. (2000): Managing flexural and angular limb deformities: the Newmarket perspective. Proc Am Assoc Equine Pract., 46:130.

Harrington, M.L.; Bagley, R.S. and Moore, M.P. (1996): Hydrocephalus. Vet. Clin North Am Small Anim Pract., 26:843-856.

Hahn, C. (2008): The nervous system. In. Color atlas of diseases and disorders of the foal (Mcauliffe, S.B. and Slovis, N.M. Eds). $1^{\text {st }}$ Ed. Saunders Ltd.pp. 347-377.

Huston, K. (1993): Heritability and diagnosis of congenital abnormalities in food animals. Vet Clin North Am Food Anim Pract., 9 (1):1-9.

IVIS. (2006): Akabane in Animal Disease Factsheets. With permission from the The Center for Food Security \& Public Health Iowa State University, Ames, IA, USA.

Johnson, J.L.; Leipold, T.T. and Hudson, D.B. (1985): Prominent congenital defects in Nebraska beef cattle. Breeding and reproduction. 4 (7):1-8.

Konno, S.; Moriwaki, M. and Nakagawa, M. (1982): Akabane Disease in Cattle: Congenital Abnormalities caused by ViralInfection. Spontaneous Disease. Vet. Pathol. 19: 246-266.
Leipold, H.W.; Mills, J.H.L. and Huston, K. (1974): Retinal dysplasia and internal hydrocephalus in ashort horn calf. Can. Vet. J., 15 (2): 34-38.

Leipold, H.W.; Hiraga T. and Dennis, S. (1993): Congenital defects of the bovine musculoskeletal system and joints. Vet Clin North Am Food Anim Pract 9 (1): 93-104.

Moritomo, Y.; Koga, O.; Miyamoto, H. and Tsuda, T. (1995): Congenital anophthalmia with caudal vertebral anomalies in Japanese Brown cattle. J. Vet. Med. Sci.; 57(4): 693-696.

Moritomo, Y.; Tsuda, T. and Miyamoto, H. (1999): Craniofacial skeletalabnormalities in anomalous calves with clefts of the face. J. Vet. Med. Sci. 61: 1147-1152.

Shaw, J.M. (1992): Hemivertebra in a crossbred heifer. Vet Rec., 1(30):538-539.

Schneider, R.K. (1989): Contracted tendons: Pathophysiology. Proc surg Forum Am Coll Vet. surg., 17:310.

Shupe, J.L.; Binns, W.; James, L.F. and Keeler, R.F. (1968): A congenital deformity in calves induced by the maternal consumption of lupin. Australian Journal of Agricultural Research. (19): 335-340

Testoni, S.; Diana, A.; Olzi, E. and Gentile, A. (2008): Brachyspina syndrome in two Holstein calves. The Veterinary Journal. 177:144-146.

Weaver, A.D. (2004): Lameness Above the Foot. In. Bovine Medicine Diseases and Husbandry of Cattle (A.H. Andrews, A.H.; Blowey, R.W.; Boyd, H. and Eddy, H. Eds). $2^{\text {nd }}$ Ed. Blackwell Science Ltd. pp. 436- 466.

Weaver, A.D.; Jean, G.S. and Steiner, A. (2005): General Considerations and Anaesthesia. In. Bovine Surgery and Lameness, Second Edition. Blackwell Publishing Ltd, UK. PP. 153.

Young, G.B. (2004): Outline of Clinical Genetics. In. Bovine Medicine Diseases and Husbandry of Cattle (A.H. Andrews, A.H.; Blowey, R.W.; Boyd, H. and Eddy, H. Eds). $2^{\text {nd }}$ Ed. Blackwell Science Ltd. pp.161-171.

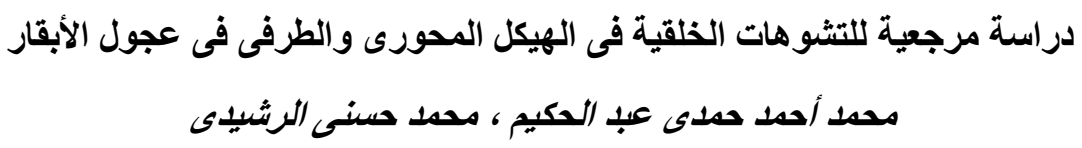

E-mail: hamdysurgery@aun.edu.eg Assiut University web-site: www.aun.edu.eg

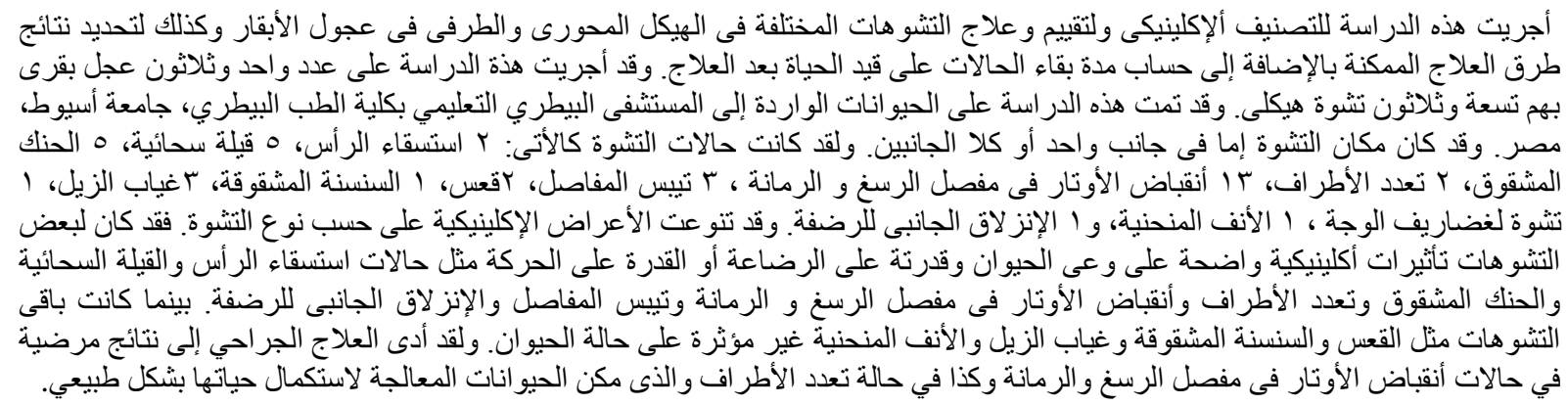

